\section{The Mediated Data Model of Communication Flow: Big Data and Data Journalism}

\author{
KOME - An International Journal of Pure \\ Communication Inquiry \\ Volume 6 Issue 2, p. 32-43. \\ (C) The Author(s) 2018 \\ Reprints and Permission: \\ kome@komejournal.com \\ Published by the Hungarian Communication \\ Studies Association \\ DOI: 10.17646/KOME.2018.23
}

\author{
Andreas Veglis ${ }^{1}$ and Theodora A. Maniou ${ }^{2}$ \\ ${ }^{1}$ Aristotle University of Thessaloniki, Media Informatics Lab, School of Journalism \& Mass \\ Communication, GREECE \\ ${ }^{2}$ Frederick University, Department of Journalism, Communication \& Mass Media, CYPRUS
}

\begin{abstract}
In recent decades, journalism has undergone considerable transformation, initially fuelled by the digitalization of journalistic work flows and subsequently by the introduction of the Internet, its services, and its effects. Since contemporary journalists employ multiple digital tools and services to gather, administrate, and process information for public consumption, new types/genres of journalism have emerged. Among these, data journalism is one of the most prominent, introduced due to the availability of data in digital form and also to the abundance of efficient online tools that help users analyze, visualize, and publish large amounts of data. Indeed, it is not only the journalistic profession that has changed, but the communication process itself, which has been fundamentally altered to meet the public's current needs and demands.

This paper introduces and examines the mediated data model of communication flow to describe these new norms in the mass communication process. Using big data as a case study and moving on to data journalism, we provide a theoretical overview of the model, employing the theory of the two-step flow of communication as a starting point, while attempting to shed light on the current communication process between journalists/media and their initial sources of information.
\end{abstract}

Keywords: Mass communication, Data Journalism, Open Data, Big Data, Mediated Communication

\title{
Introduction
}

Although communication science was officially recognised as a scientific field of study in the 1980s (Berger \& Chaffee, 1987), the complex nature of the mass communication process was acknowledged as early as the late 1930s. The next few decades were crucial and academically productive in examining the role of mass communication and the relationship between the media and their public. Between 1940 and about 1960, Paul Lazarsfeld and his team at the Bureau of Applied Social Research conducted a series of panel studies on the role of mass communication in decision-making (Katz, 1987). The theory of the two-step flow of communication, initially introduced in 1948 by Lazarsfeld, Berelson \& Gaudet, showed that the flow of mass communication was less direct than was commonly supposed, with the final Address for Correspondence: Theodora Maniou, email: manioud@yahoo.gr Article received on the 30th June, 2018. Article accepted on the 19th November, 2018.

Conflict of Interest: None 
message significantly affected by opinion leaders acting as intermediaries between the initial source and the information reaching the public.

Since then, communication studies have seen substantial developments and these initial studies have been re-evaluated several times, in the light of prevailing social, political and economic changes. The emergence of media technology and its rapid evolution to today's digital channels of communication and social media platforms have accelerated the pace of news delivery, instantly publishing at the tap of an app a story, comment, photo, video (Cushion $\&$ Sambrook, 2016) and/or live broadcasting stories. In the last 25 years, the convergence of information and communication technologies have created many new opportunities in gathering and consuming, but also in creating and disseminating news (Spyridou, Matsiola, Veglis, Kalliris \& Dimoulas, 2013). These can be mainly attributed to the introduction of the internet and its services (Veglis \& Pomportsis, 2014).

This article seeks to re-evaluate the process of mass communication in the age of big data. Its main aim is to introduce the mediated data model of communication flow, which attempts to describe these new norms. Using as a case study the example of big data and then moving on to data journalism, this article provides a theoretical overview of the mediated data model of communication flow, employing as a starting point the theory of the two-step flow of communication, while attempting to shed light on the current communication process between journalists/media and their initial sources of information. One of the most prominent elements to emerge within the framework of the mediated data model of communication flow is the important gatekeeper role of intermediaries (communication professionals employed by organisations, groups and individuals aiming to communicate data to the public), which seem to have 'replaced' the opinion leaders in affecting the quantity and quality of information that finally reaches the public.

The rest of the article is organised as follows. Section II provides the theoretical background and is divided into three sub-sections. The first subsection discusses the historical evolution of the theory of the two-step flow of communication. The second outlines current theoretical perspectives, while the third highlights the evolution of data journalism in the era of big data. Section III proposes and analyses the mediated data model of communication flow, with examples of the proposed model's application in real communication scenarios presented in the following section. Concluding remarks and future extensions of this study can be found in the last section.

\section{Theoretical Background}

\section{Historical evolution of the theory of the two-step flow of communication}

The theory of the two-step flow of communication was initially introduced in 1948 by Lazarsfeld, Berelson \& Gaudet as a hypothesis to describe the process of decision-making during the course of an electoral campaign (Lazarsfeld, Berelson \& Gaudet, 1948). However, Katz and Lazarsfeld's 1955 classic study Personal Influence: The Part Played by People in the Flow of Mass Communication indicated the significance of the two-step flow of communication. Overall, these initial studies showed that the flow of mass communication was less direct than - even at that time - was commonly supposed, since influences stemming from the media first reach opinion leaders, who, in turn, pass on the information received to their target groups.

Katz went a step further in this analysis, emphasising three distinct strands of the study: the impact of personal influence, the flow of personal influence, and the relationship between opinion leaders and mass media (Katz, 1957). This was also the first academic study to 
highlight the importance of word of mouth in the process of political communication and, later on, in the theory of agenda setting, as analysed by McCombs \& Shaw (1972) and several other significant scholars more recently (e.g., Rogers \& Dearing, 1988; Rogers, Dearing \& Bregman,1993; Scheufele, 2000).

A distinctive element of this research into the two-step flow of communication is the important role of opinion leaders. However, during the 1960s and 1970s, a number of studies pointed out weaknesses in the model. Initially, Deutschmann \& Danielson's (1960) work raised several questions, based on their assertion that media information goes directly to the public and is not relayed to any great extent. Based on this study, Troldahl (1966) was stimulated to develop a revised model of communication that raised significant questions regarding the role of opinion leaders.

In 1982, Weinmann summarised the basic controversies and revisions as follows: Westley (1971) referred to the lack of evidence of direct flow; Rogers (1962) emphasised the different stages in the diffusion process and the different sources that could be activated in each of these stages; Lin (1971) highlighted the fact that the model ignored the possibility of a continuum instead of a dichotomy among opinion leaders and non-leaders; Troldahl \& Van Dam (1965) analysed how the model ignored the process of opinion sharing rather than opinion giving; finally, Gitlin (1978) pointed out that the validity of applying the same method when measuring consumer decisions and political influence can be questionable. Noting all these weaknesses of the model and applying a cross-level network analysis, Weinmann (1982) managed to modify the two-step model of communication flow, focussing mainly on marginally positioned individuals and emphasising their bridging functional role within the communication flow between different groups of people.

Around the same period as Weinmann's study, another research study focused on the role of individual gatekeepers within the communication process between organisations/groups and their external environment. In this research, Tushman \& Katz (1980) showed that these gatekeepers performed a linking role only for locally oriented tasks, while for universally oriented tasks, direct group members' communication played the more central role. This study embraces Tushman's and Katz's (1980) analysis of 'gatekeepers', adapting their role to the context of current mass communication procedures in the digital age.

\section{Current theoretical perspectives}

The transforming role of media technology and its active evolution has been the argument and starting point for recent research to re-evaluate the two-step flow of communication. Bennet \& Manheim (2006) indicated that, due to technological changes and audience social modification, a newly formed social transformation process can lead from a two-step flow of messages to a one-step flow, involving the refined targeting of information directly to individuals. However, it is not only the decisive role of new technologies and digital practices that essentially affect the mass communication process. Significant changes in political and social contexts can also affect the overall communication process from the initial source of data transmission to the public, as can the dramatic economic transformations of recent years (Bennet \& Iyengar, 2008). Regarding the radical changes in the field of media technology, contemporary audiences have direct access to a considerable number of digital sources, ranging from mainstream media to individual blogs and digital social platforms that can directly offer a wide range of information. While these practices in the early 2000s particularly targeted younger demographics to seek coproduction of information so they could become part of the mediated communication experience (Graber, 2001), today information seekers of all age groups are extremely 
enthusiastic about embracing new networking tools and seem to rely on social/digital network platforms to manage their daily communications (Maniou \& Veglis, 2016).

Public engagement in politics has been decisively altered by these technological changes. On the one hand, younger audiences tend to engage in politics when it is perceived in their own terms (Maniou \& Eteokleous-Grigoriou, 2014), meaning that politics seems less attractive when it revolves around the old party system and more attractive when it is perceived either as identity politics or community activism (Farthing, 2010). A substantial number of young people engage in political life through 'participatory politics', which are interactive, peer-based and not guided by traditional media or political norms such as political parties (Kahn \& Middaugh, 2012). On the other hand, the overall audience, from any age and/or other demographic segment, no longer depends on the distribution of information through specific 'traditional' sources (e.g., networks, large media conglomerates, etc.) but can have access to hundreds of thousands of formal and/or informal news platforms, depending not only on availability but also on demand (Bennet \& Iyengar, 2008). The demand usually seems to be closely connected to the appealing and effortless characteristics of digital information consumption.

This newly formed 'smart audience', a globalised, active group of individuals who have incorporated the use of smart technology into their everyday life (Maniou, 2013), seems to have developed new patterns of communication, while at the same time new issues arise regarding the flow of communication and the agenda-setting process within this hybrid media environment. The role of gatekeepers is deemed essential to meet current demands in mass communication and adapts the norms of hybrid salience (Maniou \& Bantimaroudis, 2018).

The notion of certain individuals acting as agenda-setters is not a new assertion (Weinmann \& Brosius, 1994). The literature presents a wide array of evidence in relation to different types of individuals, organisations and institutions that systematically seek prominence in mediated settings. This list, apart from politicians, includes authors, cinema studios, museums, corporations and wineries, to name just a few (Guo \& McCombs, 2015; Maniou \& Bantimaroudis, 2018), associating in this way the notions of agenda setting and communicating selected messages to 'infotainment'. According to several scholars, this practice may result in encouraging citizens to contemplate politics, formulate their own ideas and speak up in political discussions, actually furthering the practice of democracy (Peters, 2015: 604-605; Cretu, 2013: 126), and facilitating the flow of information.

\section{Big data and data journalism}

The journalism profession has been considerably transformed in the last 30 years. This transformation has been fuelled initially by the digitalisation of the journalistic work flow, and later by the introduction of the internet and its services (Veglis \& Pomportsis, 2014). In the early days of Web 2.0, users could locate media content through the internet, but this was the same information, in terms both of quantity and quality, as in the traditional media; while new content was - and in several cases still is - available only via paid subscription platforms (van der Wurff, 2008). Today, news seem to have converged at spectacular speed: from smartphones to radios, television sets to tablets, newspapers to computers, the audience increasingly moves between an ever-extending menu of media platforms (Cushion \& Sambrook, 2016); nevertheless, the issue of administrating, disseminating and rapidly re-producing information remains the key factor of success for media conglomerates around the world.

Today's journalists employ many digital tools/services to gather information on breaking news and current events (Veglis \& Bratsas, 2017a). Many new types of journalism 
have emerged, including data journalism (Veglis \& Bratsas, 2017b; Gray, Chambers \& Bounegru, 2012). This new form of journalism is based on large data sets (Gray, Chambers \& Bounegru, 2012; Uskali \& Kuutti, 2015). The introduction of data journalism was helped by the availability of data in digital form, but also by the abundance of efficient online tools to analyse, visualise and publish large amounts of data (Aitamurto, Sirkkunen \& Lehtonen, 2011). It reflects the increased role of numerical data in the production and distribution of information in the digital era.

Veglis and Bratsas (2017a) defined data journalism as the process of extracting useful information from data, writing articles based on the information and embedding visualisations (interactive in some cases) in the articles that help users understand the significance of the story or allow them to pinpoint data that relate to them. A significant feature of a data journalism article is the visualisation that attempts to communicate complex information that otherwise would be difficult to convey to the readers.

It is quite obvious that one of the most important parameters in successful data journalism articles is the acquisition of data (Kayser-Bril, Valeeva \& Radchenko, 2016). The data sets can be limited in size and thus able to be managed by regular PCs; or they can be big data, which cannot be stored in a regular machine and require more advanced computer resources. The term big data was introduced in the last decade of the $20^{\text {th }}$ century, defined as data sets of a size which cannot be captured, curated, managed and processed by commonly used software running on standard personal computers (Snijders, Matzat \& Reips, 2012).

A more detailed definition was introduced by Kitchin (2014): big data is huge in volume (terabytes or petabytes), high in velocity (being created in or near real-time), diverse in variety (structured and unstructured in nature), exhaustive in scope (striving to capture entire populations or systems), fine-grained in resolution and uniquely indexical in identification, relational in nature (containing common fields that enable the conjoining of different data sets), flexible (can be extended and expanded). Journalists need to learn to work with big data and use them as a tool, an approach to information gathering and reporting. They need to acquire extra skills and utilise special software tools that will allow them to manage, understand and visualise the complex information hidden in the big datasets.

Considerable amounts of data are freely available on the internet in the form of open data. Open data can be defined as data which may be used freely, re-used and redistributed by anyone - subject only, at most, to the requirement to attribution and share alike (Dietrich, Gray, McNamara, Poikola, Pollock, Tait \& Zijlstra, 2009). Open Data Initiatives (Attard, Orlandi, Scerri \& Auer, 2015; Ramos, 2013) have played a significant role in the availability of open data. Combined with Freedom of Information legislation, this gives today's journalists unprecedented access to data. The open data movement attempts to establish transparency through the online accessibility of government data. These data may concern spending, budget, environmental pollution, etc. Therefore, data from public bodies and corporations are becoming increasingly available. The problem is that in many cases the enormous size of open data requires new methods to extract meaning from the original data, since they require extensive computational power in order to be exploited.

These developments indicate the important role of journalists in the era of big data. Ordinary people have very limited (if any) ability to access and understand the meaning of these big amounts of data. Of course, there are rare exceptions, where data literature users (in many cases considered to be hackers) are able to understand and work with big data. On the other hand, the enormous volume of big data makes it very difficult even for professional data scientists to understand them. In many cases, journalists do not have the time or ability to convey the stories hidden in the data and thus they reproduce press releases distributed along with the data sets. 
Today, data journalism does not appear to have gained momentum since it emerged at the beginning of the $21^{\text {st }}$ century (Veglis \& Bratsas, 2017a; 2017b). It is common practice for data journalism stories to be categorised as less interesting stories, published on inside pages, or as infographics, which relatively few people look at (Stoneman, 2015), and even fewer read through. Data journalism does not appear to be any closer to becoming mainstream journalism.

\section{The Mediated Data Model of Communication Flow}

The overall communication process (e.g., of political communication) could be described as follows: from the initial source, the 'transmitter', where the information is produced or actually exists, the message flows through 'intermediaries' to the media and finally heads towards the public (target audience), the 'receiver'. We claim here that the role of 'intermediaries' in current societies is not performed by opinion leaders, as described in the initial two-flow communication theory, but has been overtaken by gatekeepers: the professional communication specialists employed by organisations/institutions/individuals to manage their public profile. Initially, their role was recognised in American politics as that of professionals recruited to shape, polish and favourably mediate information regarding political candidates and/or institutions (Wilson 1996:204). Gradually, their role was extended beyond the political arena and into other societal sectors in every Western democracy, delegated to protect their overexposed clients from damage or to limit it by enticing journalists into story angles advantageous to the individuals/institutions they are working for. As a result, 'mediated publicity' has become a 24/7 presence (Gurevitch, Coleman \& Blumler, 2009) for organisations/institutions/individuals (politicians, governments, etc.) and their primary concern remains the favourable presentation through traditional as well as new media conglomerates in the current hybrid media environment.

Today, the introduction of information and communication technologies (ICTs) in the field of journalism has considerably transformed the way that a message can be transmitted from the initial transmitter to the receiver. As previously mentioned, there is a wealth of digital data and sources available online. In many cases, those datasets are quite complex (sometimes they can even be characterised as big data) and not easily understood, since they often require filtering, analysis and/or categorisation. Although internet users have access to the datasets, receiving the actual messages/stories they contain is not an easy task, although information seekers (Maniou \& Veglis, 2016) can discover such stories on their own (see path 1 in Figure 1). The traditional flow of information is channelled to the audience through media organisations. This path is described by the data journalism workflow (Veglis \& Bratsas, 2017a). Specifically, data journalists extract useful information from the datasets, write articles based on the information and utilise static or interactive visualisations (see path 2 in Figure 1). The main target of data journalism projects is to help the audience understand the significance of the story and/or offer them the ability to explore the data and find information that interests them (Veglis \& Bratsas, 2017b). 


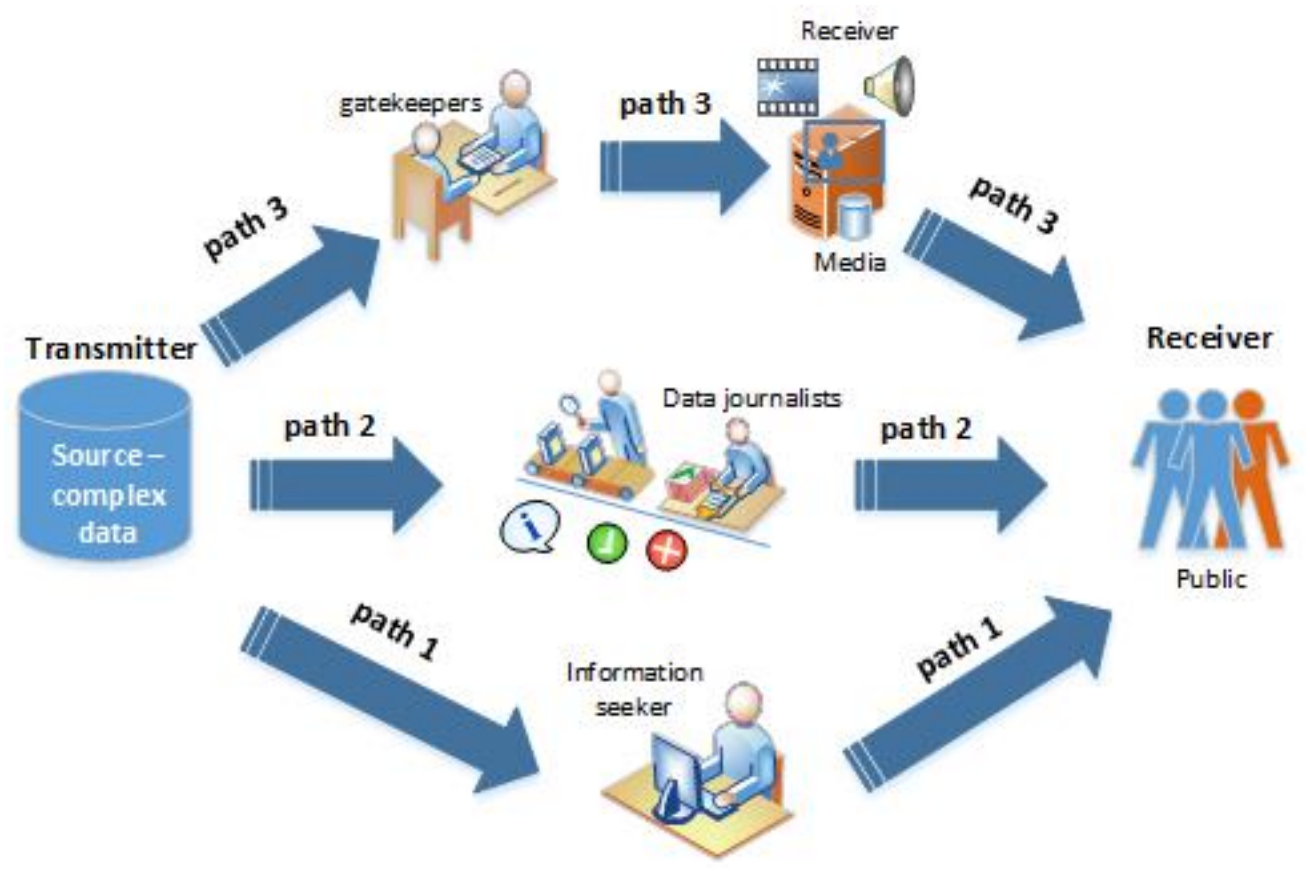

Figure 1: The Mediated Data Model of Communication Flow

The problem is that very often the enormous size of the available data and the intensive competition to be first to publish the story obliges journalists not to explore the data on their own, but to rely on communication specialists (gatekeepers) or press releases that pinpoint areas of interest in the datasets (see path 3 in Figure 1). Similar practices are also used with complex documents, which contain a significant amount of detailed information that is difficult for journalists to comprehend and administer in a limited time frame.

The proposed mediated data model of communication flow aims to describe the first stage of the overall communication process: the flow of information from the initial source through the gatekeepers towards the media. Based on the model, in this first stage the communication process cannot be considered to constitute mass communication, but is better described as a dual communication model, based on a one-dimensional character. The transmitter (the initial source) is the source where the information is produced or resides. This information is aiming to reach the media and, as such, the media (journalists) are considered the 'receiver', the target audience. Gatekeepers (communication specialists) constitute the channel (intermediary) through whom the information is filtered in ways that can reach the media (journalists) as favourably as possible for the transmitter. In this model, the group of journalists (media) are encountered by the communication specialists (intermediaries) as a unified audience group, a receiver. The one-dimensional character of this procedure refers to the transmitter's aim to administrate, communicate and emphasise those aspects of the information that are sympathetic to the transmitter itself.

Figure 1 depicts this flow of information. The focus of the mediated data model of communication is on the information flow from the source towards the media organisations. The size of the arrows indicates the likelihood that each path will be employed to transmit the message or story. It is obvious that the majority of the information flows through path 3. Path 2 is utilised in some cases and often after a time period that a related story has already been transmitted through path 3. Path 1 is employed rarely and mostly by media stakeholders that are not considered traditional media (e.g., bloggers, alternative media, citizen journalists) and have a lesser (or a different) impact on society. 


\section{Applications and Current Examples of the Model}

In order to better understand the proposed model, some examples will be briefly presented and discussed in this section. All the examples are based on the journalism profession's paramount principle of objectivity, which refers not to the absence of personal bias but rather to the basic journalistic method, a fact-based process of newsgathering (Singer, 2005).

As a first case study, let us consider parliamentary approval of a national budget. When the parliament of a democratic country discusses the national budget, journalists covering the event are given analytical reports, which in most cases constitute a book of hundreds of pages of data describing resources and expenditures as well as proposed investments for each government sector individually (education, health, public organisations, transportation systems, etc.). Complete comprehension of such a large data set would require considerable effort and time, time not usually available to the journalists who need to report the most important (at least) of these data as soon as possible. Thus, the journalists tend to base their articles on the reports which are prepared by the government officials. The way in which these reports are presented to the journalists plays a crucial role in influencing which data the journalists will choose and present to the general public. It is common practice for government officials to present favourable data for each sector prior to the data that may reveal a problematic gap in expenditures or national investments.

Another example involves crime statistics. As shown in the previous case, such data are very complex, while their understanding, critical analysis and reporting is not an easy journalistic process. Usually, such data are accompanied by executive summaries and reports that focus on specific findings on certain aspects of crime. The expected course of reporting involves articles and news stories based primarily on the information in this accompanying material (tables, figures, statistical data, etc.). Besides the element of lack of adequate time, in several cases the lack of adequate technocratic knowledge may lead to misinterpretation. In the case of the national budget, that could be a lack of macro-economic and/or micro-economic knowledge, while in the case of criminal data, it could be related to a lack of knowledge of legal and/or judicial historical artefacts.

A further example would be corporate communication strategies. According to Cornelissen (2004), communication strategies help companies to propagate information in a structured and controlled manner. The ideal communication strategy details the structure of information flow, the message and potential 'vehicles' to carry the message to existing and/or potential clients (Duncan, 2016). In addition, Morsing \& Schultz (2006) refer to specific communication actions in terms of articulating an abstract vision that is then disseminated to the target audience (stakeholders and/or potential customers). In this case, the role of intermediaries is performed by communication professionals delegated to provide the media with information presenting a favourable image of the company, such as the dissemination of corporate social responsibility activities (Maignan, Ferrell \& Hult, 1999). Corporate data in democratic societies are available to the public. However, due to the volume of data released by the company itself, following company ethics and relevant corporate law, crucial information may lie hidden among these data, which needs filtering and corporate analysis in order to be correctly understood by the affected public.

In the model, the role of gatekeepers ('intermediaries' between the initial source and the media/journalists) is crucial in the process of delivering messages whose purpose is to influence policies (Henisz \& Delios, 2004) and/or favourably present certain information to the public. As such, big data can offer a platform for 'managing' information targeting the public through journalists/media, although this procedure may result in implications for the agenda setting process as well as issues of media accountability. 


\section{Conclusions}

This article introduces and examines the mediated data model of communication flow and provides a theoretical overview of the new norms that have arisen in recent years in mass communication within the hybrid media environment. The study employs, as a starting point, the theory of the two-step flow of communication and adapts this theory to fit the current communication landscape, which involves journalists/media and their initial sources of information. Several current examples regarding the application of the mediated data model of communication flow are provided.

Overall, the present study attempts to adapt a re-evaluation of the two-step flow of communication theory in today's media landscape, which is characterised by an abundance of datasets and intense competition to be first to publish a given news story. The model advances the theoretical framework of communication theory and data journalism, aiming to shed light on the current mass communication process in a complex media environment overwhelmed by big data. The administration of big data, their filtering and dissemination to the public is a challenge every journalist has to face to cope with the public's demand for real news, as opposed to incidents of misinformation.

Undoubtedly, we are living in an era where novel information and communication technologies continuously reshape the media landscape. Communication theory also needs to adapt to the new communication environment in which the tools, stakeholders and media consumers are in a state of flux. To this end, keeping up with all the rapid developments is not an easy endeavour. The proposed mediated data model of communication flow attempts to describe the theory behind the communication and administration of the stories which are hidden in complex data. Future extensions of this study could include the application of the model to real time case studies, in order to access the validity of the model, as well as its ability to include all the parameters which may exist in such scenarios.

\section{References}

Aitamurto, T., Sirkkunen, E. \& Lehtonen, P. (2011). Trends in data journalism. Next Media, HYPERLOCAL, D.3.2.1.2.B http://virtual.vtt.fi/virtual/nextmedia/Deliverables2011/D3.2.1.2.B_Hyperlocal_Trends_In\%20Data_Journalism.pdf. Accessed 12 January 2018.

Attard, J., Orlandi, F., Scerri, S. \& Auer, S. (2015). A systematic review of open government data initiatives. Government Information Quarterly, 32 (4), 399-418. CrossRef

Bennet, L. \& Manheim, J. (2006). The one-step flow of communication. The ANNALS of the American Academy of Political and Social Science, 608, 213-232. CrossRef

Bennet, L. \& Iyengar, Sh. (2008). A new era of minimal effects? The changing foundations of political communication. Journal of Communication, 58, 707-731. CrossRef

Berger, C.R. \& Chaffee, S.H. (1987). The study of communication as a science. In C.R. Berger \& C.H. Chaffee (eds.), Handbook of Communication Science, Beverly Hills, CA: Sage, pp.1519.

Cornelissen, J. (2004). Corporate Communications: Theory and practice. London: Sage.

Cretyu, F. (2013). Just how tabloidized is tabloid press? Personalization, sensationalism and negativism in the coverage of the Romanian presidential elections, 2009. The Sphere of Politics, $174(2), 121-146$. 
Cushion, St. \& Sambrook, R. (2016). The Future of 24-hour News: New directions, new challenges. New York: Peter Lang.

Deutschmann, P. \& Danielson, W. (1960). Diffusion of knowledge of the major news stories. Journalism Quarterly, 37, 345-355.

Dietrich, D., Gray, J., McNamara, T., Poikola, A., Pollock, R., Tait, J. \& Zijlstra, T. (2009). Open Data Handbook, Open Knowledge International, http://opendatahandbook.org/. Accessed 12 January 2018.

Duncan, D. (2016). Communicating with informal sector clients: A study of strategies employed by Ghana Commercial Bank and Unibank Ghana Limited. Studies in Media and Communication, 4 (1), 1-7. $\underline{\text { CrossRef }}$

Farthing, R. (2010). The politics of youthful anti-politics: Representing the issue of youth participation in politics. Journal of Youth Studies, 13 (2), 181-195. CrossRef

Gitlin, T. (1978). Media sociology: The dominant paradigm. Theory and Society, 6, 206- 253.

Graber, D. (2001). Adapting political news to the needs of twenty-first century Americans. In W.L. Bennet \& R.M. Entman (eds.), Mediated Politics: Communication in the future of democracy, New York: Cambridge University Press, pp.422-452.

Gray, J., Chambers, L. \& Bounegru, L. (2012). The Data Journalism Handbook. http://datajournalismhandbook.org. Accessed 12 January 2018.

Guo, L. \& McCombs, M. (2015). The power of information networks: New directions for agenda setting research. New York: Routledge.

Gurevitch, M., Coleman, St. \& Blumler, J. (2009). Political communication: Old and new media relationships. The ANNALS of the American Academy of Political and Social Science, 625, 164-181. CrossRef

Henisz, W. \& Delios, A. (2004). Information or influence? The benefits of experience for managing political uncertainty. Strategic Organisation, 2 (4), 389-421. $\underline{\text { CrossRef }}$

Kahn, J. \& Middaugh, E. (2012). Digital media shapes youth participation in politics. Kappan, $94(3), 52-56$.

Katz, E. \& Lazarsfeld, P. (1955). Personal Influence: The part played by people in the flow of mass communication. New York: Free Press.

Katz, E. (1957). The two-step flow of communication: an up-to-date report on an hypothesis. Public Opinion Quarterly, 21, 67-78. CrossRef

Katz, E. (1987). Communications research since Lazarsfeld. Public Opinion Quarterly, 51 (4 Part 2): S25-S45. https://doi.org/10.1093/poq/51.4_PART_2.S25. Accessed 12 January 2018.

Kayser-Bril, N., Valeeva, A. \& Radchenko, I. (2016). Transformation of communication processes: Data journalism. XVI April International Academic Conference on Economic and Social Development, 3, 414-421.

Kitchin, R. (2014). Big data, new epistemologies and paradigm shifts. Big Data \& Society, 1 (1), 1-12. $\underline{\text { CrossRef }}$ 
Lazarsfeld, P., Berelson, B. \& Gaudet, H. (1948). The People's Choice. New York: Columbia University Press.

Lin, N. (1971). The Study of Human Communications. Indianapolis: Bobbs-Merrill.

Maignan, I., Ferrell, O.C. \& Hult, G.T.M. (1999). Corporate citizenship: Cultural antecedents and business benefits. Journal of the Academy of Marketing Science, 27 (4), 455-469. CrossRef

Maniou, Th. (2013). Traditional media in transition? The reliability of political news in the new media age. Mediterranean e-Journal of Communications and Media, 2 (1). http://mediaejournal.org/traditional-media-in-transition/ Accessed 12 January 2018.

Maniou, Th. \& Eteokleous-Grigoriou, N. (2014). Television vs Web 2.0 in the new media age: The effects of information upon university students. Communication Studies, 16, 1-32.

Maniou, Th. \& Veglis, A. (2016). Selfie journalism: Current practices in digital media. Studies in Media and Communication, 4 (1), 111-118. CrossRef

Maniou, Th. \& Bantimaroudis, Ph. (2018). Hybrid salience: Examining the role of traditional and digital media in the rise of the Greek radical left. Journalism, 1-18. CrossRef

McCombs, M. \& Shaw, D. (1972). The agenda-setting function of mass media. Public Opinion Quarterly, 36 (2), 176-187. CrossRef

Morsing, M. \& Schultz, M. (2006). Corporate social responsibility communication. Business Ethics: A European Review, 15 (4), 323-338. CrossRef

Peters, C. (2015). Evaluating journalism through popular culture: HBO's the newsroom and public reflections on the state of the news media. Media, Culture \& Society, 37 (4), 602-619. CrossRef

Ramos, E. (2013). A journalist's take on open data. In B. Goldstein and L. Dyson (eds), Beyond Transparency: Open data and the future of civic innovation, San Francisco, CA: Code for America Press, available at http://beyondtransparency.org/pdf/BeyondTransparency.pdf. Accessed December 12 $2^{\text {th }}, 2017$.

Rogers, E. (1962). Diffusions and Innovations. New York: Free Press.

Rogers, E. \& Dearing, J. (1988). Agenda-setting research: Where has it been, where it is going? Annals of the International Communication Association, 11 (1), 555-594. CrossRef

Rogers, E., Dearing, R. \& Bregman, D. (1993). The anatomy of agenda-setting research. Journal of Communication, 43 (2), 68-84. CrossRef

Scheufele, D. (2000). Agenda setting, priming and framing revisited: Another look at cognitive effects of political communication. Mass Communication \& Society, 3 (2 \& 3), 297-316. CrossRef

Singer, J. (2005). The political j-blogger: 'Normalizing' a new media form to fit old norms and practices. Journalism, 6 (2), 173-198. $\underline{\text { CrossRef }}$

Snijders, C., Matzat, U. \& Reips, U.D. (2012). Big data: Big gaps of knowledge in the field of internet. International Journal of Internet Science, 7, 1-5. 
Spyridou, L.P., Matsiola, M., Veglis, A., Kalliris, G. \& Dimoulas, C. (2013). Journalism in a state of flux: Changing journalistic practices in the Greek newsroom. International Communication Gazette, 75 (1), 76-98. $\underline{\text { CrossRef }}$

Stoneman, J. (2015). Does open data need journalism? Working Paper, Reuters Institute for the Study of Journalism. https://reutersinstitute.politics.ox.ac.uk/sites/default/files/research/files/Stoneman\%2520\%2520Does\%2520Open\%2520Data\%2520need\%2520Journalism.pdf Accessed 12 January 2018.

Troldahl, V. \& Van Dam, R. (1965). Face-to-face communication about major topics in the news. Public Opinion Quarterly, 29, 626-634. CrossRef

Troldahl, V. (1966). A field test of a modified 'two-step flow of communication' model. Public Opinion Quarterly, 30 (4), 609-623. CrossRef

Tushman, M. \& Katz, R. (1980). External communication and project performance: An investigation into the role of gatekeepers. Management Science, 26 (11), 1071-1085. CrossRef

Uskali, T. \& Kuutti, H. (2015). Models and streams of data journalism. The Journal of Media Innovations, 2 (1), 77-88.

van der Wurff, R. (2008). The effects of internet upon media content. In Kung, L., Picard, R. \& Towse, R. (eds), The Internet and the Mass Media, London: Sage, pp.91-115.

Veglis, A. \& Pomportsis, A. (2014). Journalists in the age of ICTs: Work demands and educational needs. Journalism \& Mass Communication Educator, 69 (1), 61-75. CrossRef

Veglis, A. \& Bratsas, C. (2017a). Reporters in the age of data journalism: The case of Greece. Journal of Applied Journalism \& Media Studies, 6 (2), 225-244. CrossRef

Veglis, A. \& Bratsas, C. (2017b). Towards a taxonomy of data journalism. Journal of Media Critiques, 3 (11), 109-121. CrossRef

Weinmann, G. (1982). On the importance of marginality: One more step into the two-step flow of communication. American Sociological Review, 47, 764-773. CrossRef

Weinmann, G. \& Brosius, H.B. (1994). Is there a two-step flow of agenda-setting? International Journal of Public Opinion Research, 6, 323-341. CrossRef

Westley, B. (1971). Communication and social change. American Behavioral Scientist, 14, 719-742. CrossRef

Wilson, J. (1996). Understanding Journalism: A guide to issues. London: Routledge. 